\title{
Kalça Kırığı Nedeniyle Cerrahi Tedavi Uygulanan 65 Yaş Üstü Hastaların Bir Yıllık Mortalite Oranları
}

\author{
Yalçın TURHAN in ${ }^{1}$, Mehmet ARICAN [i] $^{1}$
}

\section{ÖZ}

Amaç: Yaşlı hastalarda sık gözlenen kalça kırıkları ciddi morbidite, maluliyet ve hatta artmış mortalite ile yakından ilişkilidir. Bu çalışmada kalça kırığı sebebiyle cerrahi tedavi uygulanan hastaların, cerrahiden sonraki ilk bir yılda gözlenen mortalite oranı ve buna etki eden faktörlerin incelenmesi amaçlanmıştır.

Gereç ve Yöntemler: Kliniğimizde Ekim 2014-Şubat 2018 tarihleri arasında izole intertrokanterik femur ya da femur boyun kırıkları nedeniyle cerrahi tedavi uygulanan 65 yaş üzeri 164 hasta geriye dönük olarak incelendi. Arşiv kayıtları üzerinden hastalara ait yaş, cinsiyet, kırık tipi, yatış-cerrahi arası zaman, cerrahi-taburculuk arası zaman ve kırık için uygulanan implant tipi gibi gerekli bilgilere ulaşıldı. Ayrıca hastalara telefon ile ulaşılarak vefat tarihleri (vefat etti iseler) öğrenildi. Hastalar; cerrahi sonrasındaki ilk bir yıl içinde vefat edenler ve yaşayanlar olarak iki gruba ayrıldı ve mortaliteye etki eden faktörler açısından karşılaştırmalı analizler yapıldı.

Bulgular: Çalışmaya kriterlere uygun 138 hasta dahil edildi. Cerrahi sonrası ilk 1 yıldaki ölüm oranı \%21,73 olarak bulundu. Vefat edenler grubunun yaş ortalaması $(85,97 \pm 7,49)$ yaşayanlar grubundan $(79,02 \pm 8,92)$ istatistiksel olarak anlamlı derecede yüksek bulundu $(\mathrm{p}=0,0001)$. Vefat edenler grubundaki kadın hasta oranı yaşayanlar grubundan istatistiksel olarak anlamlı derecede yüksek bulundu $(\mathrm{p}=0,037)$. Vefat edenler ve yaşayanlar grupları arasında kırık tipi ve uygulanan implant türü açısından anlamlı derecede farklılık gözlenmedi $(p=0,881$ ve $p=0,101)$. Vefat edenler grubunun yatış-cerrahi arası süre ile cerrahi-taburculuk arası süre ortalamaları yaşayanlar grubundan istatistiksel olarak anlamlı derecede yüksek bulundu ( $\mathrm{p}=0,034$ ve $\mathrm{p}=0,0001$ ).

Sonuç: $\mathrm{Bu}$ çalışmada cerrahi sonrası ilk bir yıldaki mortalite oranı $\% 21,73$ olarak bulundu ve mortaliteye etki eden en önemli faktörlerin ileri yaş ile artmış yatış-cerrahi ve cerrahi-taburculuk arası süre olduğu tespit edildi.

Anahtar Kelimeler: Kalça kırıkları; ölüm oranı; kalça replasman artroplasti; intrameduler çivileme.

\section{One-Year Mortality Rates of Patients with Surgically Treated Hip Fractures over the Age of} 65

\begin{abstract}
Aim: Fractures of the hip are frequently seen in the elderly patients and closely related to severe morbidity, disability, and even increased mortality. The aim of this study was to evaluate the first year mortality rate and the factors affecting this in the patients with surgically treated hip fractures.

Material and Methods: In this retrospective study, 164 patients aged over 65 years who had undergone surgery in our clinics for isolated intertrochanteric femur or femoral neck fractures between October 2014 and February 2018 were evaluated. The necessary information such as age, gender, type of fracture and applied implant, the times between hospitalization/surgery and surgery/discharge were obtained from the archive records. In addition, the patients were contacted by phone and the death times (if they died) were learned. Patients were divided into two groups as who died in the first year after surgery and survived; and then factors affecting the mortality were analyzed comparatively.

Results: This study included 138 patients who meet eligibility criteria. One year mortality rate after surgery was $21.73 \%$. The mean age of the death group (85.97 \pm 7.49$)$ was statistically significantly higher than the survival group $(79.02 \pm 8.92)(p=0.0001)$. The ratio of the female patients in the death group was found to be statistically significantly
\end{abstract}

1 Düzce Üniversitesi, Tıp Fakültesi, Ortopedi ve Travmatoloji A.D., Düzce, Türkiye 
higher than the survival group $(\mathrm{p}=0.037)$. There were not any statistically significant difference between the death and survival groups in terms of fracture and applied implant types $(p=0.881$ and $p=0.101)$. The mean times between hospitalization/surgery and surgery/discharge were statistically significantly higher in the death group $(\mathrm{p}=0.034$ and $\mathrm{p}=0.0001)$.

Conclusion: In this study, the mortality rate in the first year after surgery was found to be $21.73 \%$ and the most important factors affecting this rate were determined as advanced age and increased times between hospitalization/surgery and surgery/discharge.

Keywords: Hip fractures; death rate; hip replacement arthroplasty; intramedullary nailing.

\section{GíRIŞ}

Endüstrideki gelişmelere paralel olarak beklenen ortalama insan ömrü tüm dünyada artmakta ve buna sekonder yaşlı nüfusta ciddi artışlar gözlenmektedir. Fiziksel kapasitedeki azalmalar, eşlik eden sistemik problemler ve kemik kitlesindeki kayıplar da yaşlı hastalarda gözlenen basit travmalara bağlı kırık riskini artırmaktadır (1). Altmış yaş üzeri hastalarda gözlenen kalça kırığı bu popülasyonda gözlenen kemik lezyonlarının \%84'lük kısmını oluşturur ve ciddi bir halk sağlığı sorunu olmanın yanında mortalite, maluliyet ve artmış hastane masraflarının majör sebebi olarak karşımıza çıkmaktadır (2). Proksimal femurda basit travmaya sekonder gözlenen kırıklar genellikle intertrokanterik ya da boyun bölgesinde gözlenmektedir. Hastaların büyük bir kısmında cerrahi tedavi endikasyonu olmakla birlikte; deplasmanı olmayan inkomplet kırıklarda ve klinik durumu cerrahiye uygun olmayan bazı seçilmiş hastalarda konservatif tedavi seçeneği düşünülebilmektedir. Hastanın klinik durumu da göz önünde bulundurularak cerrahi tedavinin ideal olarak travmanın 24 ile 48. saatleri arasında uygulanması önerilmektedir (3). Kalça kırığı sonrası beklenen yaşam süresinin normal yaşlı nüfusa oranla azaldığı ve kırık sonrası ilk 1 yılda ölüm oranının \%20 civarında olduğu bildirilmektedir (4). Birçok çalışmada artmış yaş, erkek cinsiyet, fiziksel durum ve gecikmiş tedavinin mortaliteyi belirleyen esas faktörler olduğu vurgulanmıştır $(5,6)$. Intertrokanterik femur kırığı nedeniyle cerrahi uygulanan hastaların femur boyun kırığ 1 hastalarına göre daha ileri yaşta oldukları ve fonksiyonel düzelmelerinin daha kötü olduğu rapor edilmiştir ancak tedavide kullanılan implant türünün hastaların mortalitesi ile doğrudan ilgisinin olmadığını gösteren çalışmalar da mevcuttur $(7,8)$. Bu çalışmada; basit düşme sonrası kalça kırığı gelişen ve cerrahi olarak tedavi edilen 65 yaş üstü hastalarda; cerrahiden sonraki ilk 1 yıl içinde gözlenen mortalitenin kırık, uygulanan implant tipi ve cerrahi zamanlama ile ilişkisinin incelenmesi amaçlanmaktadır.

\section{GEREÇ VE YÖNTEMLER}

Hastanemiz Ortopedi ve Travmatoloji Kliniği acil servisine Ekim 2014 - Şubat 2018 tarihleri arasında basit düşme sonrası kalça kırığı nedeni ile başvurarak cerrahi tedavi uygulanmış olan hastalar geriye dönük olarak değerlendirildi. Çalışma öncesinde Düzce Üniversitesi Tıp Fakültesi Klinik Araştırmalar Etik Kurulu tarafından onay alınmıştır (No: 2019/19). Değerlendirilen hastalardan; 65 yaş üstü olup izole kalça kırığı teşhisi konularak cerrahi tedavi uygulanmış olan hastalar çalışmaya dahil edildi. Uygulanan cerrahi sırasında 65 yaş altında olan, kalça kırığı nedeniyle konservatif tedavi uygulanan, çoklu travmaya sekonder eşlik eden kırıkları olan, cerrahi uygulanmadan ya da taburcu olmadan vefat eden, patolojik kırığı olan ve daha önce aynı kalçaya ait geçirilmiş cerrahi öyküsü olan hastalar çalışma dişı birakıld1.

Arşiv dosyaları ile hastane belge yönetim sistemi (HBYS) kayıtları üzerinden hastalara ait; yaş, cinsiyet, kırık tipi, kırık sonrası cerrahiye kadar geçen süre, operasyon tarihi, kırık tedavisinde uygulanan yöntem ve cerrahiden sonra taburculuğa kadar geçen süre gibi bilgiler elde edildi. AO (Arbeitsgemeinschaft für Osteosynthesefragen) siniflamasina göre 31-A (İntertrokanterik femur kırıkları-ITFF) ve 31-B (Femur boyun kırıkları-FBK) kırıklar çalışmaya alındı. Aynı zamanda hastaların tedavisi için uygulanmış olan implantlar da [çimentosuz parsiyel endoprotez (PEP), çimentolu parsiyel endoprtotez (ÇPEP), proksimal femoral çivi (PFN) ve kalkar replasmanlı parsiyel endoprotez (KPEP)] incelenerek grupland. Ek olarak hastalara telefon yolu ile ulaşılarak hastaların -eğer vefat ettilerse- vefat tarihleri sorgulandı ve cerrahiden kaç ay sonra vefat ettikleri hesaplanarak kayıt altına alındı.

\section{İstatistiksel Analiz}

Çalışmada istatistiksel analizler NCSS (Number Cruncher Statistical System) 2007 (Utah, USA) paket programı ile yapılmıştır. Verilerin değerlendirilmesinde tanımlayıcı istatistiklerin hesaplanmasının (ortalama, standart sapma, medyan, birinci ve üçüncü çeyreklikler) yanı sıra Kolmogorov Smirnov normallik testi ile değişkenlerin dağılımına bakılmış, normal dağılım gösteren değişkenlerin ikili grupların karşılaştırmasında Bağımsız Örneklemler $t$ testi, normal dağılım göstermeyen değişkenlerin ikili grupların karşılaştırmasında Mann Whitney U testi, nitel verilerin karşılaştırmalarında Ki-kare testi kullanılmıştır. Sonuçların anlamlılığı $\mathrm{p}<0,05 \quad$ düzeyinde değerlendirilmiştir.

\section{BULGULAR}

Arşiv ve HBYS kayıtları üzerinden yapılan inceleme sonucu Ekim 2014 - Şubat 2018 tarihleri arasında kalça kırığı nedeniyle cerrahi tedavi uygulanmış olan 65 yaş üzeri 164 hasta değerlendirildi. Bu hastalardan telefon yolu ile ulaşılarak istenen bilgileri tamamlanabilen 138 hasta çalışmaya dahil edildi. Hastaların 88'i $(\% 63,77)$ kadın, 50'si (\%36,23) erkekti. Tüm hastaların yaş ortalaması ise $80,53 \pm 9,07$ olarak bulundu. Hastaların 89'unda $(\% 64,49)$ ITFF, 49'unda ise $(\% 35,51)$ FBK tespit edildi. Kırk dokuz FBK hastasının tamamına PEP (\%100), 89 ITFF hastasinın ise 6'sina $(\% 6,74)$ PEP, 15’ine $(\% 16,85)$ ÇPEP, 30'una $(\% 33,71)$ PFN ve 38'ine $(\% 42,70)$ KPEP uygulanmış olduğu gözlendi. Cerrahi sonrası ilk 1 yılın sonunda 30 hastanın $(\% 21,73)$ vefat ettiği ve 108 hastanın $(\% 78,2)$ sağ kaldığ 1 tespit edilmiştir. Hastalar postoperatif 1 yıl içinde vefat edenler ve 1 yıldan daha uzun süre sağ kalanlar olarak gruplandı. Tablo 1'de vefat edenler ve sağ kalanlar gruplarının; yaş, cinsiyet, kırık tipi, kullanılan implant türü ve cerrahi zamanlamaya göre kıyaslanması özetlenmiştir. 
Tablo 1. Vefat edenler ve sağ kalanlar gruplarının; yaş, cinsiyet, kırık tipi, kullanılan implant türü ve cerrahi zamanlamaya göre kıyaslanması

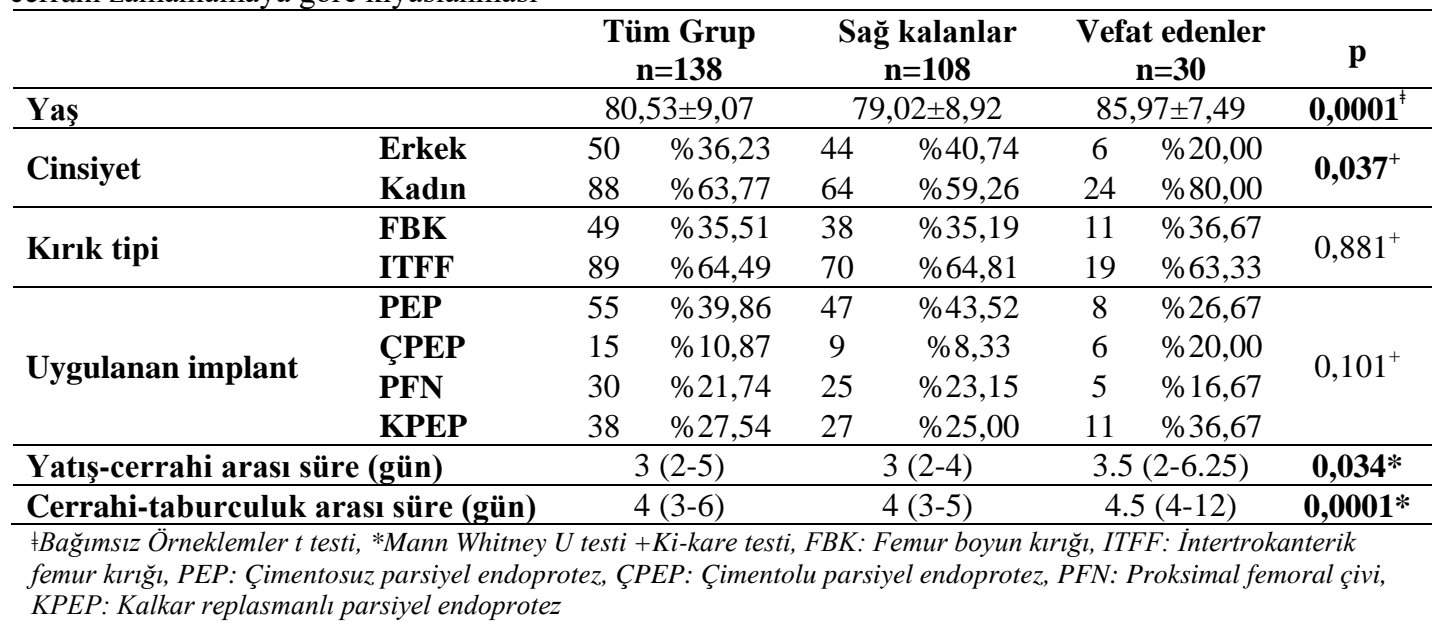

Vefat edenler ve sağ kalanlar gruplarının cinsiyet dağılımları arasında istatistiksel olarak anlamlı derecede farklılık gözlenmiştir; vefat edenler grubundaki kadın hasta oranı sağ kalanlar grubundan istatistiksel olarak anlamlı derecede yüksek bulunmuştur $(p=0,037)$. Vefat edenler ve sağ kalanlar grupları arasında kırık tipi açısından anlamlı derecede farklılık gözlenmemiştir $(p=0,881)$. Yine vefat edenler ve sağ kalanlar grupları arasında uygulanan implant türü açısından da anlamlı derecede farklılık gözlenmemiştir $(p=0,101)$. Vefat edenler grubunun yatış-cerrahi arası süre medyan değerleri sağ kalanlar grubundan istatistiksel olarak anlamlı derecede yüksek bulunmuştur $(p=0,034)$. Benzer şekilde vefat edenler grubunun cerrahi-taburculuk arası süre medyan değerleri de sağ kalanlar grubundan istatistiksel olarak anlamlı derecede yüksek bulunmuştur $(p=0,0001)$.

\section{TARTIŞMA}

$\mathrm{Bu}$ çalışmada yaşlı hastalarda gözlenen kalça kırığı nedeniyle uygulanan cerrahi tedavi sonrası ilk 1 yıldaki mortalite oranları ve bu mortaliteye neden olan faktörler incelendi. Çalışma sonucunda tüm kalça kırıklarındaki 1 y1llık mortalite oranı \%21,73 olarak bulundu. Literatürdeki birçok çalışmada 1 y1llık mortalite oranlarının $\% 20$ ila $\% 35$ aralığında bulunduğu bildirilmektedir (9-11).

Kalça kırıklarının kadınlarda daha sık olduğu yaygın olarak bilinen bir gerçektir ve literatürde kalça kırığının kadınlarda erkeklere oranla iki ila dört kat daha fazla gözlendiği bildirilmektedir $(8,12,13)$. Çalışmamızda ise kadın erkek oranı yaklaşık 3/2 olarak bulundu. Aharonoff ve ark. (14) 1997 yılında yaptıkları çalışmada 1 yıllık mortalite ile cinsiyet arasında fark saptanmadiğ bildirilmektedir. Buna karşın Endo ve ark. (15) 2005 yılında yaptıkları çalışmada erkeklerde artmış mortalite oranları bildirilmiştir. Yine Holt ve ark. (13) 2008 yılında yaptıkları ve 18817 hastayı içeren geniş serilerinde kadınlarda daha az postoperatif mortalite bildirilmiştir. Çalışmamızda da vefat edenler grubundaki kadın hasta oranları sağ kalanlar grubundan anlamlı derecede yüksek bulunmuştur $(p=0,037)$.

Artan yaşla birlikte kalça kırı̆̆ı insidansının da arttığını ve birçok çalışmada tespit edilen ortalama yaşın 80 yaş civarında olduğunu bilmekteyiz; buna paralel olarak bu çalışmadaki hastaların yaş ortalaması da $80,53 \pm 9,07$ olarak bulundu $(8,16)$. Pugely ve ark. (17) tarafindan 2014 yılında yapılan ve 4331 hastanın prospektif olarak incelendiği bir çalışmada 80 yaş üzeri hastalarda mortalite oranının ciddi şekilde arttığı ve ileri yaşın mortalite ile doğrudan ilişkili olduğu gösterilmiştir. Benzer olarak çalışmamızda yer alan hastaların yaş ortalamas1 vefat edenler grubunda $85,97 \pm 7,49$ ve sağ kalanlar grubunda ise 79,02 $\pm 8,92$ bulunmuş ve bu farkın istatistiksel olarak anlamlı olduğu tespit edilmiştir $(\mathrm{p}=0,0001)$.

Hastalarda mevcut olan kalça kırı̆̆ı tipi ile cerrahi sonrasındaki ilk bir yılda gözlenen mortalite arasındaki ilişkinin incelendiği birçok çalışmada kırık tipinin mortaliteyi direk etkileyen bir faktör olmadığ gösterilmiştir $(7,18,19)$. Neuhaus ve ark. (20) 2013 yılında yaptıkları bir çalışmada ise ITFF'nin FBK'ya göre daha yüksek mortalite oranları ile ilişkili olduğu gösterilmiş ancak bu çalışmada bir yıllık mortalite değil hastanede yatış sırasında gözlenen mortalite oranları incelenmiştir. Çalışmamızda da literatür ile uyumlu olarak kırık tipinin mortalite üzerine etkisi gösterilememiştir $(\mathrm{p}=0,881)$. Kullanılan implant türü ile mortalite arasındaki ilişkiyi inceleyen çalışmalarda çelişkili sonuçlar bildirilmekle birlikte genel kanı, kullanılan implant türünün de mortalite üzerine direk etkisi olmadığı yönündedir $(7,8,10,18)$. Mevcut çalışmada kullanılan dört farklı implant türünün de bir yıllık mortalite üzerine etkisi olmadığı tespit edilmiştir $(\mathrm{p}=0,101)$.

Kalça kırığı gelişiminden cerrahi tedavi uygulanıncaya kadar geçen sürenin artması bazı otörlere göre mortaliteyi direk olarak etkilemektedir $(6,21,22)$. Buna karşın Öztürk ve ark. (23) 2008 yilında ve Guerra ve ark. (7) 2017 yılında yaptıkları çalışmalarda verilen sonuçlar, bu sürenin mortalite ile doğrudan ilişkisi olmadığ yönündedir. Çalışmamızda ise bu süreler birbirine yakın olmakla birlikte vefat edenler grubunda anlamlı düzeyde yüksek bulunmuştur $(p=0,034)$. Literatürde toplam hastanede kalış ve cerrahi sonrası taburculuk dönemine kadar olan süre yüksekliğinin de mortaliteyi artırdığını gösteren çalışmalar mevcuttur $(7,24)$. Mevcut çalışmada da cerrahi sonrası taburculuğa kadar geçen sürenin sağ 
kalanlar grubuna oranla vefat edenler grubunda anlamlı derecede yüksek olduğu gösterilmiştir $(\mathrm{p}=0,0001)$.

\section{SONUÇ}

Kalça kırığ 1 nedeniyle cerrahi tedavi uygulanmış olan 65 yaş üstü hasta grubu ile yapılan bu çalışmada; cerrahi sonrası ilk bir yıldaki mortalite oranı \%21,73 olarak bulunmuş ve mortaliteye etki eden en önemli faktörlerin ileri yaş ile yatış-cerrahi ve cerrahi-taburculuk arası süre olduğu tespit edilmiştir. İleri yaş grubunda sık olarak karşımıza çıkan kalça kırıkları sonrası hastaların hastanede kalış sürelerinin mümkün olan en alt seviyede tutulması, mortalite oranlarının azaltılmasına yönelik katkılar sağlayabilir.

\section{KAYNAKLAR}

1. Vidan M, Serra JA, Moreno C, Riquelme G, Ortiz J. Efficacy of a comprehensive geriatric intervention in older patients hospitalized for hip fracture: A randomized, controlled trial. J Am Geriatr Soc. 2005; 53(9): 1476-82.

2. Diamantopoulos AP, Rohde G, Johnsrud I, Skoie IM, Johnsen $\mathrm{V}$, Hochberg $\mathrm{M}$, et al. Incidence rates of fragility hip fracture in middle-aged and elderly men and women in southern Norway. Age and Ageing. 2012; 41(1): 86-92.

3. Griffiths EJ, Cash DJ, Kalra S, Hopgood PJ. Time to surgery and 30-day morbidity and mortality of periprosthetic hip fractures. Injury. 2013; 44(12): 1949-52.

4. Pande I, Scott DL, O’Neill TW, Pritchard C, Woolf AD, Davis MJ. Quality of life, morbidity, and mortality after low trauma hip fracture in men. Ann Rheum Dis. 2006; 65(1): 87-92.

5. Lustosa LP, Bastos EO. Fraturas proximais do fêmur em idosos: Qual o melhor tratamento? Acta Ortop Bras. 2009; 17(5): 309-12.

6. Daugaard CL, Jorgensen HL, Riis T, Lauritzen JB, Duus BR, vander Mark S. Is mortality after hip fracture associated with surgical delay or admission during weekends and public holidays? A retrospective study of 38,020 patients. Acta Orthop. 2012; 83(6): 609-13.

7. Guerra MTE, Viana RD, Feil L, Feron ET, Maboni J, Vargas ASG. One-year mortality of elderly patients with hip fracture surgically treated at a hospital in Southern Brazil. Revista Brasileira de Ortopedia. 2017; 52(1): 17-23.

8. Ribeiro TA, Premaor MO, Larangeira JA, Brito LG, Luft M, Guterres LW, et al. Predictors of hip fracture mortality at a general hospital in South Brazil: An unacceptable surgical delay. Clinics (Sao Paulo). 2014; 69(4): 253-8.

9. Ricci G, Longaray MP, Gonçalves RZ, Ungaretti Neto AS, Manente M, Barbosa LBH. Avaliação da taxa de mortalidadeem um ano após fratura de quadril e fatores relacionados àdiminuição da sobrevida no idoso. Rev Bras Ortop. 2012; 47(3): 304-9.

10. Pereira SR, Puts MT, Portela MC, Sayeg MA. The impact of prefracture and hip fracture characteristics on mortality in older persons in Brazil. Clin Orthop Relat Res. 2010; 468(7): 1869-83.
11. Meessen JM, Pisani S, Gambino ML, Bonarrigo D, van SchoorNM, Fozzato S, et al. Assessment of mortality risk in elderly patients after proximal femoral fracture. Orthopedics. 2014; 37(2): 194-200.

12. Belmont PJ Jr, Garcia EJ, Romano D, Bader JO, Nelson KJ, Schoenfeld AJ. Risk factors for complications and in-hospital mortality following hip fractures: A study using the National Trauma Data Bank. Arch Orthop Trauma Surg. 2014; 134(5): 597604.

13. Holt G, Smith R, Duncan K, Finlayson DF, Gregori A. Early mortality after surgical fixation of hip fractures in the elderly: An analysis of data from the Scottish hip fracture audit. The Journal of Bone and Joint Surgery (British vol). 2008; 90(10): 1357-63.

14. Aharonoff GB, Koval KJ, Skovron ML, Zuckerman JD. Hip fracture in the elderly: Predictors of one year mortality. J Orthop Trauma. 1997; 11(3): 162-5.

15. Endo Y, Aharanoff GB, Zuckerman JD, Egol KA, Koval KJ. Gender differences in patients with hip fracture: A greater risk of morbidity and mortality in men. J Orthop Trauma. 2005; 19(1): 29-35.

16. Frost SA, Nguyen ND, Center JR, Eisman JA, Nguyen TV. Excess mortality attributable to hipfracture: A relative survival analysis. Bone. 2013; 56(1): 23-9.

17. Pugely AJ, Martin CT, Gao Y, Klocke NF, Callaghan JJ, Marsh JL. A risk calculator for short-term morbidity and mortality after hip fracture surgery. J Orthop Trauma. 2014; 28(2): 63-9.

18. Dubljanin-Raspopović E, Marković-Denić L, Marinković J, Nedeljković U, Bumbaširević M. Does early functional outcome predict 1-year mortality in elderly patients with hip fracture? Clin Orthop Relat Res. 2013; 471(8): 2703-10.

19. Vaseenon T, Luevitoonvechkij S, Wongtriratanachai $\mathrm{P}$, Rojanasthien S. Long-term mortality after osteoporotic hip fracture in Chiang Mai, Thailand. J Clin Densitom. 2010; 13(1): 63-7.

20. Neuhaus V, King J, Hageman MG, Ring DC. Charlson comorbidity indices and in hospital deaths in patients with hip fractures. Clin Orthop Relat Res. 2013; 471(5): 1712-9.

21. Khan SK, Rushton SP, Dosani A, Gray AC, Deehan DJ. Factors influencing length of stay and mortality after first and second hip fractures: An event modeling analysis. J Orthop Trauma. 2013; 27(2): 826.

22. Baker DM. Postoperative complications and mortality associated with operative delay in older patients who have a fracture of the hip. J Bone Joint Surg Am. 1997; 79(3): 470.

23. Öztürk I, Toker S, Ertürer E, Aksoy B, Seçkin F. Kalça kırığı nedeniyle ameliyat edilen 65 yaş üstü hastalarda mortaliteye etki eden risk faktörlerinin değerlendirilmesi. Acta Orthop Traumatol Turc. 2008; 42(1): 16-21.

24. Astur DC, Arliani GG, Balbachevsky D, Fernandes HJ, Reis FB. Fraturas da extremidade proximal do fêmur tratadas no Hospital São Paulo/Unifesp Estudo epidemiológico. RBM Espec Ortop. 2011; 68(4): 11-5. 